depth. The well informed patient and relative will probably be happier and less likely to call on NHS facilities unnecessarily. While acute illness is usually dealt with effectively and promptly, the doubts and bewilderment accompanying the diagnosis of a prolonged or lifelong illness deserve and demand our response.

Money may be needed for rooms, an information person, and an administrator/welcomer. The teaching sessions would mostly be run by people not needing pay. Diabetologists have already set an example on education: why should we not follow?

Department of General Medicine,

C J Burns-Cox Frenchay Hospital,

Bristol BS16 1LE

SIR,-The National Self-Help Support Centre welcomes Dr Stephen Lock's article and would like to take this opportunity to join in the debate he has opened up.

It might be helpful for those of us still trying to define self help to see participating in a self help group as part of a process of accepting a handicap, disability, or illness and learning to cope with it for as long as necessary. How useful it must be then for doctors, other health professionals, and social workers to participate in this process too. They are not to become members of the self help group, but they can be "resource people" to the group. We strongly believe in the valuable contribution professionals can make to self help groups, and our activities, which include producing a newsletter and training materials and running workshops and networks, are aimed at developing ideas and practice about supporting groups.

Participating in a self help group cannot replace any of the health services. Neither should it be seen as an alternative form of treatment. We could not agree more with the comment "By no means every patient or relative will benefit from joining a group." For some people help comes from sharing with a friend or talking to a therapist or counsellor. Furthermore, joining a group comes after a person has recognised his or her handicap or illness. This in itself raises some deep seated questions about identity and may delay the decision to take part in a group.

Nevertheless, the existence of self help groups and their recognition by health professionals widen people's choice. Members of a group find out more about the possible causes of their problem, how to cope with the symptoms, and the range of treatment available. They also have a chance to hear themselves articulate their problem and gradually begin to come to terms with it. Participating in a self help group can be part of the curing process. This is why we should all support and encourage the existence of self help groups irrespective of whether we are members, relatives, or professionals.

NOREEN MILLER

National Self-Help Support Centre,

London WC1B 3HU

Dose dependent response of symptoms, pituitary, and bone to transdermal oestrogen in postmenopausal women

SIR,-Dr J C Stevenson and his colleagues (17 January, $p$ 181) appear to believe that the relation we have established between plasma oestradiol and its biological actions (22 November, $p$ 1337) is invalid since they hold that the measured responses are "suboptimal." There is no logical or biological basis for this notion: an optimal response may make the measurement of an effect more certain but its absence does not invalidate the doseresponse curve. Furthermore, we contend that the responses are less "suboptimal" than they believe.

Firstly, although they cite Coope's study as showing that the frequency of flushing does not return to the pretreatment rate until at least two months after oestrogen withdrawal, ${ }^{1}$ they fail to point out that by one month after oestrogen withdrawal the frequency rose to that in the placebo group and indeed after two months was greater than the pretreatment rate. In other studies of transdermal oestradiol the washout period after oestrogen has been four weeks, ${ }^{2} 30$ days, ${ }^{3}$ and six weeks, ${ }^{4}$ and so our period of one month is in line with that of other investigators. In our study only eight of our 26 women had previously received oestrogens; of these, five had stopped a month before the study and the other three had not received oestrogen for 8 weeks, 26. weeks, and 3 years. Thus even using the criteria of $\mathrm{Dr}$ Stevenson and his colleagues for oestrogen deficiency the proportion of partially oestrogenised patients was about the same as in Mr Whitehead's own study, in which $25 \%$ of the patients had high endogenous oestradiol values.'

Secondly, Mr Whitehead's study is cited to maintain that three weeks is not long enough to assess the effect of transdermal oestradiol..$^{5}$ Again, this is at variance with the findings of other investigators, all of whom found significant effects of transdermal oestradiol on the frequency of hot flushes by three ${ }^{2}$ and four $r^{4}$ weeks. Indeed, in Coope's study of oral oestrogen replacement the response on switching from placebo to oestrogen was complete by three weeks.'

As for the postmenopausal score, we are grateful for the opportunity to expand on a necessarily abbreviated section of our paper. The symptoms (frequency of hot flushes, vaginal dryness, libido, irritability, depression, and unusual tiredness) were given equal weighting and scored according to severity from 0 (absent) to 4 (severe) by two experienced physicians (MP, PLS). The questionnaire was based on published studies ${ }^{67}$ has been used for over a decade in our menopause clinic, and has been accepted in many publications. We have no reason to believe that we are not as capable of performing this clinical assessment as general practitioners and gynaecologists. It is stated but not documented that the responses about symptoms are valid only if one person records the symptom score, and, although we have no data on the variance of the score within and between individuals, we would assume that the variability between observers would act against us and make a significant difference between basal and treated scores more difficult to demonstrate. The patch size is irrelevant since each patient received only one size of patch and had no idea of its oestrogen content.

The statistical analysis was based on a paired $t$ test between untreated and treated values, as described, and the line drawn was arbitrary, "not arbitrary drawn through the means," which is a solecism. The term "congruent" is used in its literal sense of "agreeing" although there is no reason why it cannot be used in its geometric sense with arbitrary drawn lines. As we expected from the small numbers of patients chosen for each dose group, analysis of variance showed no differences between the dose groups. The object of our study was not to provide definitive dose-response curves, which would require many more patients, but to establish whether transdermal oestradiol reduced gonadotrophin release, bone resorption, and post menopausal symptoms over the same range of plasma oestradiol concentrations. This it clearly did.

The fact that these three actions become asymptotic at a plasma oestradiol concentration above $150 \mathrm{pmol} / \mathrm{l}$ does suggest that plasma concentrations above this are unlikely to confer additional benefits and, because it is generally accepted that adverse effects are dose related ${ }^{8}$ likely to cause an increasing incidence of side effects. Furthermore, because the pituitary (via receptors) and bone (via a mechanism unknown) appear to have similar dose-response and time curves ${ }^{910}$ and because we have previously shown no effect of oestrogen on free calcitriol, parathyroid hormone, and calcitonin over this time period $^{9-11}$ we maintain that the results in this study do support our hypothesis ${ }^{10} 12$ that the oestrogen effect on bone resorption is receptor mediated. This action on bone is associated with a resetting of the secretion thresholds of the calcium regulating hormones and not with a change in their plasma concentrations.

MRC Mineral Metabolism Unit,

MunRo Peacock General Infirmary, Leeds LS1 3EX

Department of Medicine,

Peter Selby

Medical School,

Newcastle upon Tyne NE2 4HH

1 Coope J. Double-blind cross-over study of estrogen replacement therapy. In: Campbell S, ed. Management of the menopause and therapy. In: Campbell S, ed. Management of the menopaus

2 Laufer LR, De Fazio JL, Lu JKH, et al. Estrogen replacement herapy by transdermal estradiol administration. Am $\mathcal{f}$ Obste Gynecol 1983;146:533-8.

3 Powers MS, Schenkel L, Darley PE, et al. Pharmacokinetics and pharmacodynamics of transdermal dosage forms of $17 \mathrm{\beta}$ estradiol: comparison with oral estrogens used for hormone replacement. Am J Obstet Gynecol 1985;152:1099-106.

4 Chetkowski RJ, Meldrum DR, Steingold KA, et al. Biological effects of transdermal estradiol. N Engl f Med 1986;314: 1615-20.

5 Padwick ML, Endacott J, Whitehead ME. Efficacy, acceptability and metabolic effects of transdermal estradiol in the management of postmenopausal women. Am $\mathcal{F}$ Obstet Gynecol 1985;152:1085-91.

6 Jones MM, Marshall DH, Nordin BEC. Quantitation of menopausal symptomatology and its response to ethinyl oestradiol and piperazine oestrone sulphate. Curr Med Res Opin 1977;4:12-20.

7 Nordin BEC, Jones MM, Crilly RG, et al. A placebo-controlled trial of ethinyl oestradiol and norethisterone in climacteric women. Maturitas 1980;2:247-51.

8 Vessy MP, Bungay GT. Benefits of risks of hormone therapy in the menopause. In: Smith A, ed. Recent advances in community medicine. Edinburgh: Churchill Livingstone, 1982: 77-94.

9 Selby PL, Peacock M, Barkworth SA, $e t$ al. Early effects of ethinyloestradiol and norethisterone treatment in postmenopausal women on bone resorption and calcium regulating pausal women on bone resorption

10 Selby PL, Peacock M. Ethinyl estradiol and norethindrone in the treatment of primary hyperparathyroidism in postmenopausal women. N Engl f Med 1986;314:1481-85.

11 Selby PL, Peacock $M$. The effect of transdermal oestrogen on bone, calcium regulating hormones and liver in postmenopausal women. Clin Endocrinol 1986;25:543-8.

12 Peacock M, Selby PL, Francis RM, Taylor GA. The action and biological significance of female and male sex steroids on plasma total and free $1,25(\mathrm{OH})_{2} \mathrm{D}$, parathyroid hormone and calcitonin. In: Norman AW, Schaefer K, eds. Vitamin D: chemical, biochemical and clinical update. Berlin: Walter de Gruyter, 1985: 595-6.

\section{Lung cancer and passive smoking}

SIR,-Your article by Professor Nicholas Wald and others (8 November, $p$ 1217) on passive smoking and lung cancer contained a statistical analysis which was essentially repeated in a report of a committee of the National Research Council of the United States. Professor Wald was a member of that committee and apparently was the principal architect of the epidemiological aspects of that work. ${ }^{1}$

A contemporaneous survey of epidemiological studies on passive smoking and lung cancer was given in an editorial by Blot and Fraumeni in the fournal of the National Cancer Institute. ${ }^{2}$ The published reports covered by Professor Wald and colleagues and by Blot and Fraumeni largely overlapped. Substantially similar estimates of relative risk were arrived at, 1.34 or 1.35 , and in both cases were nominally significant.

Similar concerns about bias were expressed, specifically that women reporting themselves as non-smokers might actually be active smokers or ex-smokers and that non-smoking women not exposed to smoking at home might still have some exposure away from home. Other possibly more serious biases in the studies conducted were not considered. (These include publishing bias: if an investigator got a weakly or insignificantly negative result for the role of passive smoking in lung cancer would he bother submitting it for publication? And if he did, would it be accepted? There seems to be a tendency towards accepting uncritically or 